\title{
Špecifické aspekty spracovania geodetických sietí použitím programu SoNet
}

\author{
Marián Kováč, Ján Hefty \\ Department theoretical geodesy \\ Faculty of Civil Engineering, Slovak University of Technology \\ E-mail: marian.kovac@stuba.sk, jan.hefty@stuba.sk
}

Kl'účové slová: geodetické siete, vyrovnanie

\begin{abstract}
Abstrakt
Článok je zameraný na popis programu na spracovanie geodetických sietí s analyticky definovaným matematickým modelom (observačné rovnice definované v programe v symbolickom tvare), čo je najvýraznejšia črta, ktorou sa program odlišuje od súčasných programov na spracovanie geodetických sietí.

Univerzálnost programu demonštrujeme na príklade spracovania viacepochovej geodetickej siete. Spracovanie bolo uskutočnené vo forme prípadových štúdii od elementárnej kombinácie merani GPS s uvážením kovariančných matíc, až po spoločné spracovanie terestrických observácí a GPS s uvážením časových zmien a transformačných parametrov v spoločnom matematickom modeli.
\end{abstract}

\section{Úvod}

Jednou zo základných úloh geodézie je budovanie geodetických sietí. Geodetické siete tvoria množinu geodetických bodov, ktoré sú účelne rozložené na zemskom povrchu. Tvoria základ pre štúdium tvaru, rozmerov a tiažového pola Zeme a sú aj podkladom pre všetky druhy technických a meračských prác.

Význam a úloha geodetických sietí sa s rozvojom geodézie mení a upravuje. Klasický prístup k budovaniu, resp. spracovaniu geodetických sietí sa zameriava na oddelené spracovanie polohových, výškových a tiažových meraní a označuje sa ako dvojrozmerná geodézia. S rozvojom družicových metód, ich dostupnostou a presnost’ou nastáva v geodézii problém, ako tieto merania čo najlepšie využit’ a nestratit informáciu o trojrozmernej polohe bodov. Takisto nastáva problém, ako tieto merania čo najlepšie spojit’ s terestrickými a gravimetrickými meraniami. Vzniká potreba zjednotit’ dostupné merania v spoločnom matematickom modeli.

Pojem štvorrozmernej geodézie sa používa pre tie geodetické teórie, metódy spracovania a interpretácie, ktoré sa venujú určovaniu priestorovej polohy bodov súčasne s opisom ich zmien $\mathrm{v}$ čase.

\section{Softvérová aplikácia}

Motivácia. K vytvoreniu softvéru s analyticky definovaným matematickým jadrom nás viedli nasledovné zistenia: 
- V geodézi sa v súčasnosti spracovávajú rôzne typy geodetických sietí (terestrické, gravimetrické, GPS, ...) spravidla tak, že na každý typ geodetickej siete, resp. na ich určitú skupinu je potrebný iný program.

- Matematický model na vyrovnanie geodetických sietí (ak predpokladáme vyrovnanie sprostredkujúcich meraní) je v princípe založený na poznaní vztahu medzi meranými veličinami a neznámymi, ktoré sú viazané funkčným vztahom nazývaným observačná rovnica.

Prezentovaný program je navrhnutý ako modulárny systém, kde základnú aplikáciu je možné rozšírit o (a) zásuvné moduly a (b) skripty (v jazyku Python). Vstupný údajový formát programu je v jazyku XML [4]. Tento vstupný súbor zahŕňa (a) čast', v ktorej je popísaný matematický model siete, (b) čast’ obsahujúcu samotné observácie.

\section{Geodetické observácie}

V programe je možné spracovávat nasledovné geodetické observácie (v zátvorke je uvedený príslušný XML element): geocentrické karteziánske súradnice (coordinate), resp. ich parametrický vektor, zmeny priestorovej polohy (velocity), horizontálny uhol (angle), zenitový uhol (z-angle), priestorová vzdialenost' (distance), prevýšenie (diffh). Vo vstupnom súbore sa napr. vodorovný uhol zapíše v tvare (zo stanoviska A):

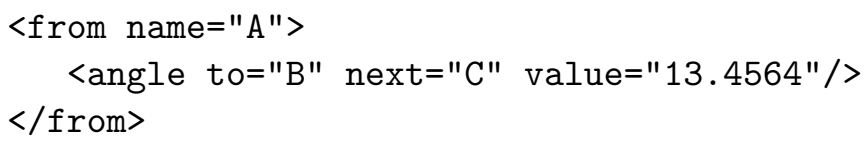

Program umožňuje spracovávat viacepochové geodetické siete; jednotlivé epochy sa v programe označujú pojmom unit. Každý unit zapúzdruje observácie združené v časti označenej pojmom block. Každný block obsahuje okrem observácií aj im prislúchajúcu kovariančnú maticu. Príklad unitu s jedným blockom, jednou dĺžkou a prislúchajúcou kovariančnou maticou:

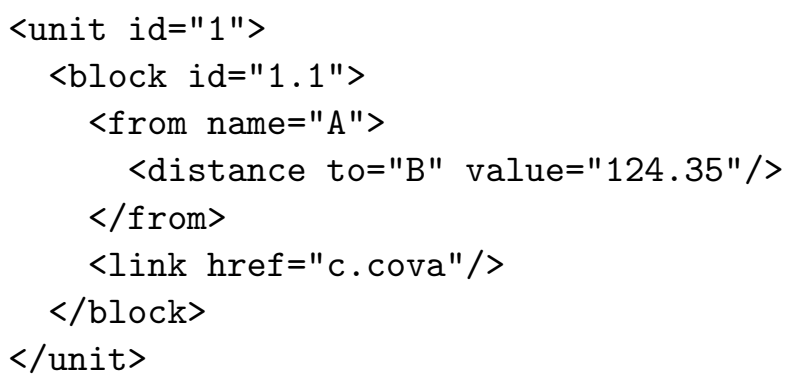

\section{Matematický model}

Matematický model je v programe definovaný analyticky. Pri jeho zostavovaní je potrebné uviest' (a) observácie (observations), ktoré chceme spracovat', (b) neznáme odhadované parametre (unknowns) v symbolickom tvare (vo forme textového retazca) a (c) observačné rovnice (equations) v symbolickom tvare, ktoré viažu observácie s definovanými neznámymi parametrami. 


\section{Výber neznámych parametrov}

Pomocou neznámych parametrov je možné v programe definovat' neznáme, ktoré chceme z vyrovnania získat́. Neznáme parametre sa definujú v elemente unknown. Každý element unknown obsahuje element group, ktorý združuje elementy point, pomocou ktorých je definované, ku ktorým bodom je definovaná neznáma vztiahnutá. Ak príslušná skupina (element group) má definovaný atribút name, označuje sa ako pomenovaná skupina, ak ho definovaný nemá, označuje sa príslušná skupina ako anonymná. Význam anonymnej skupiny je v tom, že pre každý bod definovaný v tejto skupine sa vytvorí samostatná neznáma; príkladom anonymnej skupiny môže byt napr. definovanie odhadovaných súradníc, ai. Naopak, pri pomenovanej skupine sa vytvorí jedna neznáma viazaná ku všetkým bodom obsiahnutým v pomenovanej skupine; príkladom pomenovanej skupiny môže byt napr. definovanie transformačných parametrov, ktoré sa viažu k viacerým bodom. Príklad pomenovanej skupiny:

<unknowns>

<unknown type="omega ['\\omega',g, 63.66197,cc,100,5]:

psi ['\\psi',g,63.66197,cc,100,5]:

epsilon ['\\epsilon', g, 63.66197, cc, 100,5]">

<group name="second">

$<$ point name $=" \cdot * " />$

$</$ group $>$

$</$ unknown $>$

$</$ unknowns $>$

\section{Observačné rovnice}

Definovanie observačných rovníc s neznámymi a observáciami tvorí základnú filozofiu aplikácie. Vo všeobecnej teórii odhadu observačné rovnice zabezpečujú väzbu medzi observáciami, ktoré sú predmetom merania a určovanými neznámymi parametrami, ktoré sú predmetom (cielom) odhadu. Vo všeobecnosti je matematický, resp. deterministiký model tvorený práve observačnými rovnicami, ktoré je možné v aplikácii l'ubovolne definovat’ a modifikovat'.

Observačné rovnice sa v programe SoNet zapisujú v symbolickom tvare. V observačných rovniciach je možné použit l'ubovolné matematické operátory a štandartné matematické funkcie. Príklad jednoduchej observačnej rovnice nivelácie je v nasledujúcej ukážke:

$h\{i, j\}=H\{j\}-H\{i\}$

kde v zátvorkách sú indexy príslušnej observácie, resp. neznámych odhadovaných parametrov. Okrem observácií a odhadovaných neznámych je možné v observačných rovniciach použit aj d'alšie premenné, ktorými sú metainformácie a parametre elipsoidov načítané z externých súborov.

Derivácie observačných rovníc. Program SoNet vykonáva automaticky rozvoj zostavených observačných rovníc do Taylorovho radu, resp. automatické derivovanie týchto observačných rovníc, tzn. linearizácia observačných rovníc je riešená analyticky. 


\section{Metainformácie}

Metainformácie umožňujú zaradenia určitých číselných hodnôt do spracovania tak, aby sa tieto dali použit v symbolickom tvare v observačných rovniciach. Č́selnými hodnotami reprezentujúcimi metainformácie môžu byt’ napr. časové značky, hodnoty teploty, tlaku, výšky teodolitov a terčov, ai.

Jednotlivé metainformácie sú obsiahnuté v elemente meta. V nasledujúcej ukážke je znázornené použitie týchto atribútov $\mathrm{v}$ elemente meta:

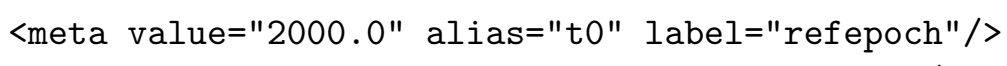

\section{Príklad}

\section{Siet’ jadrovej elektrárne Mochovce}

V rokoch 1988 a 1989 sa uskutočnili opakované merania lokálnej geodetickej siete Mochovce pomocou terestrických geodetických metód (merania dížok a vodorovných uhlov). Schématické znázornenie meraných veličín je na obr. 1. V rokoch 2001, 2002, 2003 sa uskutočnili geodetické merania vybranej časti siete Mochovce metódou GPS (obr. 2) [6,7].

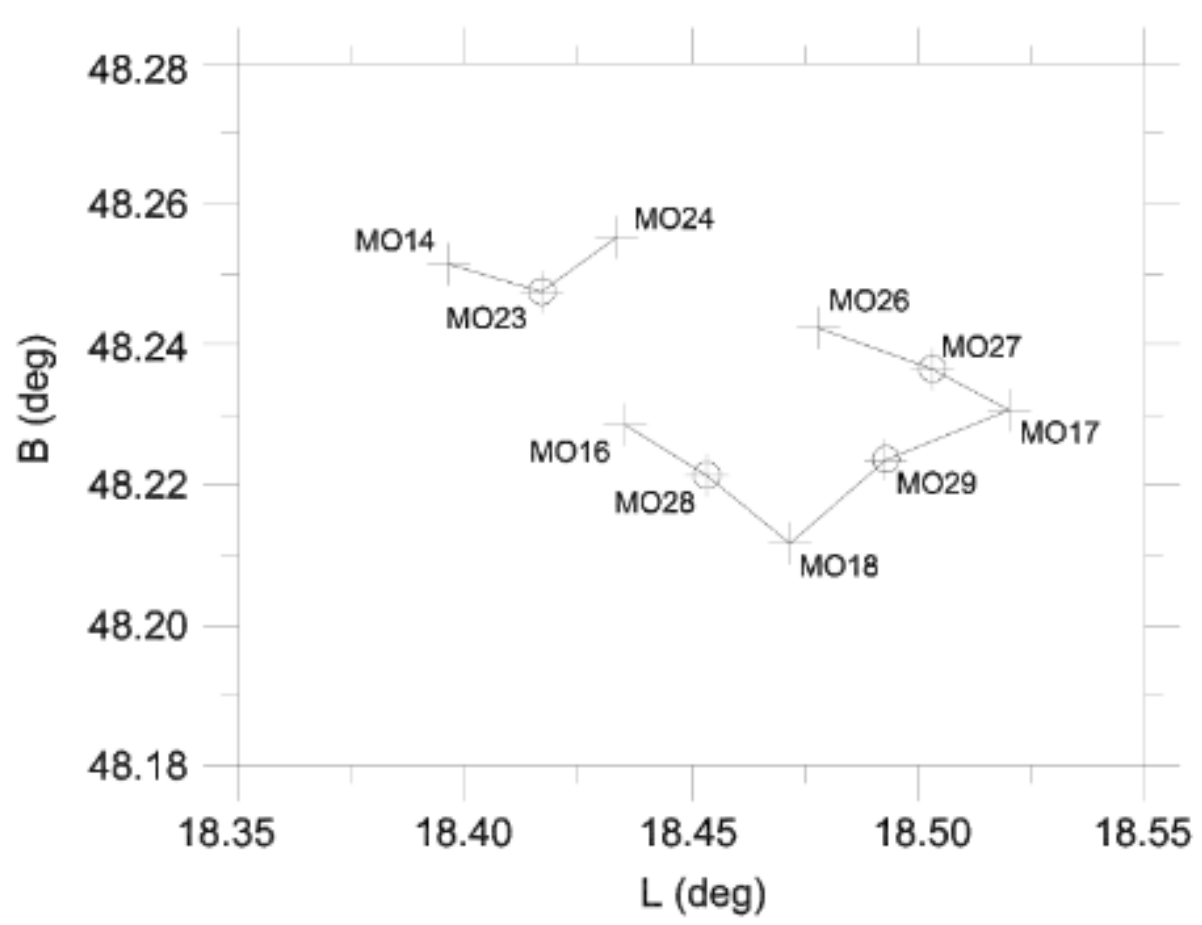

Obrázok 1: Terestrické observácie; symbolom o sú označené body, na ktorých bolo vykonané uhlové meranie, symbolom — sú označené merania dížok medzi bodmi geodetickej siete. 


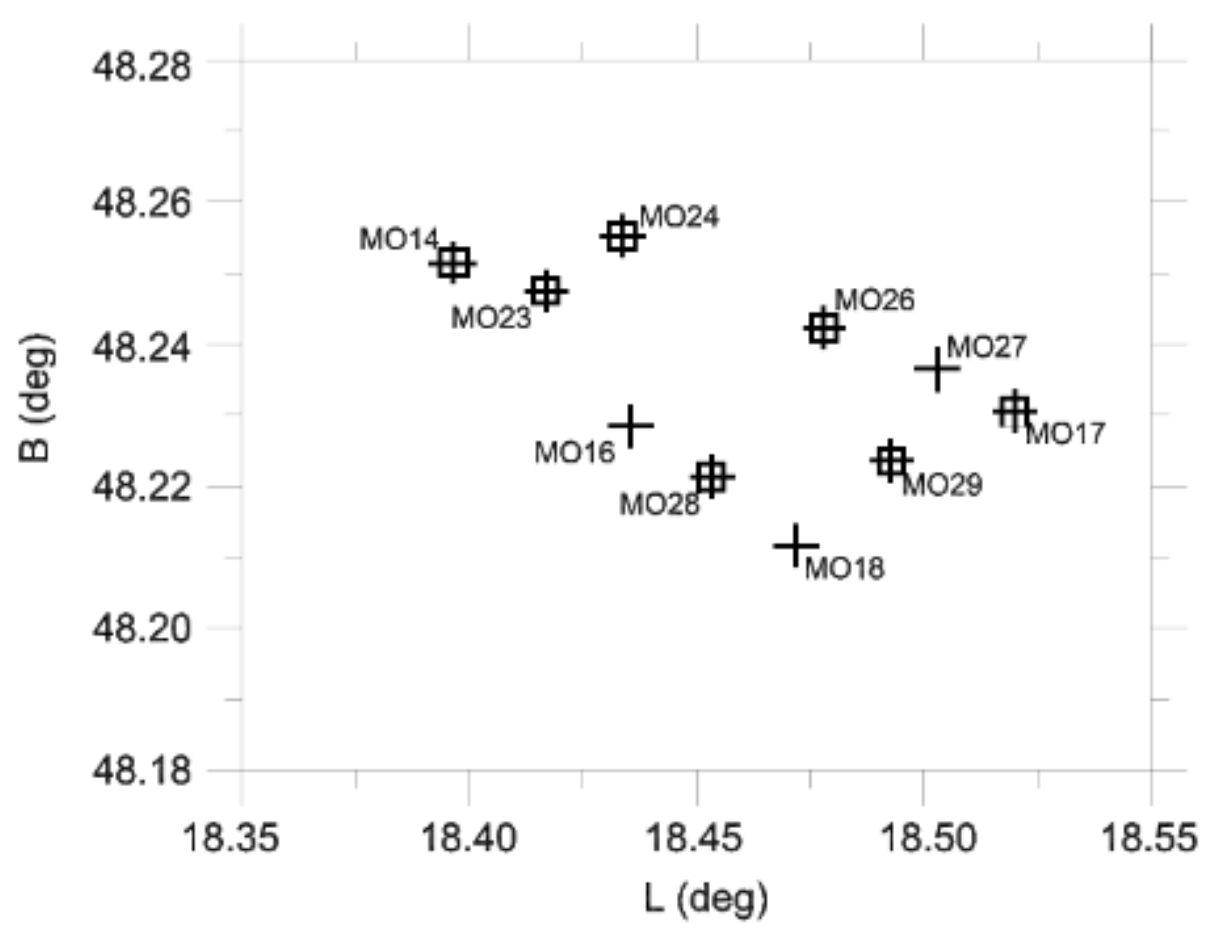

Obrázok 2: Body merané pomocou GPS, symbolom $\square$ sú označené body merané aspoň v dvoch kampaniach v období $2001-2003$.

\section{Matematický model}

Predmetná geodetická siet’ bola spracovaná vo viacerých variantoch. Tu je prezentované spoločné spracovanie terestrických meraní a GPS s odhadom súradníc, rýchlostí a transformačných parametroch je realizované modelom [5] (upravené):

$$
\left(\begin{array}{c}
\mathbf{x}^{\left(t_{1}\right)} \\
\mathbf{x}^{\left(t_{2}\right)} \\
\vdots \\
\mathbf{x}^{\left(t_{n}\right)} \\
\mathbf{l}^{\left(t_{1}\right)} \\
\mathbf{l}^{\left(t_{2}\right)} \\
\vdots \\
\mathbf{l}^{\left(t_{n}\right)}
\end{array}\right)=\left(\begin{array}{ccccc}
\mathbf{I}^{\left(t_{1}\right)} & \mathbf{D}^{\left(t_{1}\right)} & \mathbf{0} & \cdots & \mathbf{0} \\
\mathbf{I}^{\left(t_{2}\right)} & \mathbf{D}^{\left(t_{2}\right)} & \mathbf{T}^{\left(t_{2}\right)} & \cdots & \mathbf{0} \\
\vdots & \vdots & \vdots & \ddots & \vdots \\
\mathbf{I}^{\left(t_{n}\right)} & \mathbf{D}^{\left(t_{n}\right)} & \mathbf{0} & \cdots & \mathbf{T}^{\left(t_{n}\right)} \\
\mathbf{A}_{l}^{\left(t_{1}\right)} & \mathbf{D}_{l}^{\left(t_{1}\right)} & \mathbf{0} & \cdots & \mathbf{0} \\
\mathbf{A}_{l}^{\left(t_{2}\right)} & \mathbf{D}_{l}^{\left(t_{2}\right)} & \mathbf{0} & \cdots & \mathbf{0} \\
\vdots & \vdots & & & \\
\mathbf{A}_{l}^{\left(t_{p}\right)} & \mathbf{D}_{l}^{\left(t_{p}\right)} & \mathbf{0} & \cdots & \mathbf{0}
\end{array}\right)\left(\begin{array}{c}
\mathbf{y} \\
\mathbf{v}_{y} \\
\boldsymbol{\Theta}^{\left(t_{2}\right)} \\
\vdots \\
\boldsymbol{\Theta}^{\left(t_{n}\right)}
\end{array}\right)
$$

s kovariančnou maticou 


$$
\boldsymbol{\Sigma}=\left(\begin{array}{cccccccc}
\boldsymbol{\Sigma}^{\left(t_{1}\right)} & \mathbf{0} & \cdots & \mathbf{0} & \mathbf{0} & \mathbf{0} & \mathbf{0} & \mathbf{0} \\
\vdots & \vdots & \ddots & \vdots & \vdots & \vdots & \vdots & \vdots \\
\mathbf{0} & \mathbf{0} & \cdots & \boldsymbol{\Sigma}^{\left(t_{m}\right)} & \mathbf{0} & \mathbf{0} & \mathbf{0} & \mathbf{0} \\
\mathbf{0} & \mathbf{0} & \mathbf{0} & \mathbf{0} & \boldsymbol{\Sigma}_{l}^{\left(t_{1}\right)} & \mathbf{0} & \cdots & \mathbf{0} \\
\vdots & \vdots & \vdots & \vdots & \vdots & \vdots & \ddots & \vdots \\
\mathbf{0} & \mathbf{0} & \mathbf{0} & \mathbf{0} & \mathbf{0} & \mathbf{0} & \cdots & \boldsymbol{\Sigma}_{l}^{\left(t_{p}\right)}
\end{array}\right)
$$

kde $\mathbf{I}^{\left(t_{i}\right)}$ je matica väzieb medzi observáciami v $i$-tej epoche a odhadovanými súradnicami, $\mathbf{A}_{l}^{\left(t_{i}\right)}$ je matica väzieb medzi terestrickými observáciami v $i$-tej epoche a odhadovanými geocentrickými karteziánskymi súradnicami, $\mathbf{D}^{\left(t_{i}\right)}, \mathbf{D}_{l}^{\left(t_{i}\right)}$ je diagonálna matica definujúca väzbu medzi rýchlostami a pozorovaniami v $i$-tej epoche pre GPS a terestrické observácie, $\mathbf{T}^{\left(t_{i}\right)}$ je matica väzieb medzi observáciami a odhadovanými súradnicami, $\mathbf{x}^{\left(t_{i}\right)}$ je vektor realizácií v $i$-tej epoche, $\mathbf{l}^{\left(t_{i}\right)}$ sú terestrické observácie $\mathrm{v} i$-tej epoche, $\boldsymbol{\Sigma}^{\left(t_{i}\right)}$ je kovariančná matica súradníc určených z GPS v $i$-tej epoche, $\boldsymbol{\Sigma}_{l}^{\left(t_{i}\right)}$ je kovariančná matica terestrických observácií $\mathrm{v} i$-tej epoche, y sú výsledné súranice vztiahnuté k referenčnému rámcu 1. epochy, $\mathbf{v}_{y}$ sú odhadnuté rýchlosti bodov, a $\boldsymbol{\Theta}^{\left(t_{i}\right)}$ sú odhadnuté transformačné parametre.

\section{Matematický model definovaný vo vstupnom súbore programu}

Matematická formulácia observačných rovníc pre geocentrické karteziánske súradnice:

$$
\begin{aligned}
x_{i} & =x_{0_{i}}+t_{x}+v_{x_{i}}\left(t-t_{0}\right) \\
y_{i} & =y_{0_{i}}+t_{y}+v_{y_{i}}\left(t-t_{0}\right) \\
z_{i} & =z_{0_{i}}+t_{z}+v_{z_{i}}\left(t-t_{0}\right)
\end{aligned}
$$

Zápis týchto rovníc v programe:

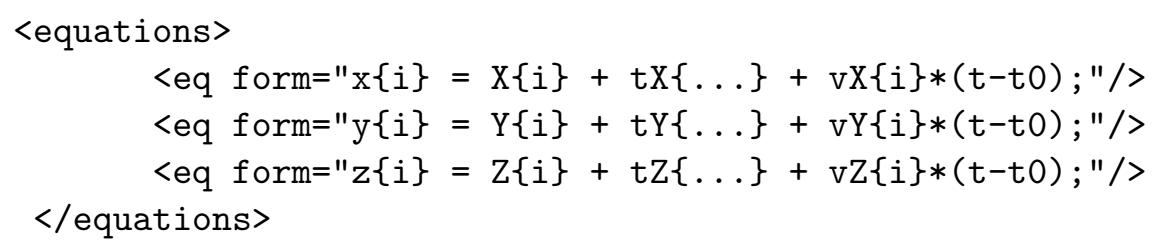

Matematická formulácia priestorovej dížky:

$$
\begin{array}{cc}
s_{i j}= & \\
& \left(\left(X_{j}+v_{X_{j}}\left(t-t_{0}\right)-X_{i}-v_{X_{i}}\left(t-t_{0}\right)\right)^{2}+\right. \\
& \left(Y_{j}+v_{Y_{j}}\left(t-t_{0}\right)-Y_{i}-v_{Y_{i}}\left(t-t_{0}\right)\right)^{2}+ \\
& \left.\left(Z_{j}+v_{Z_{j}}\left(t-t_{0}\right)-Z_{i}-v_{Z_{i}}\left(t-t_{0}\right)\right)^{2}\right)^{1 / 2}
\end{array}
$$

Zápis observačnej rovnice priestorovej dížky v programe:

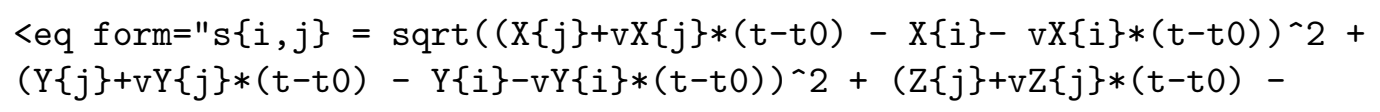


$\left.Z\{i\}-v Z\{i\} *(t-t 0))^{\wedge} 2\right) ; "$

/>

Matematická formulácia vodorovného uhla ako rozdiel dvoch smerov:

$$
\begin{aligned}
\omega_{i j k}= & -\sin L_{i}\left(\Delta X_{i k}+\Delta v_{X_{i k}}\right)+\cos L_{i}\left(\Delta Y_{i k}+\Delta v_{Y_{i k}}\right) \\
- & \arctan \frac{-\sin L_{i}\left(\Delta X_{i j}+\Delta v_{X_{i j}}\right)+\cos L_{i}\left(\Delta Y_{i j}+\Delta v_{Y_{i j}}\right)}{-\sin B_{i} \cos L_{i}\left(\Delta X_{i k}+\Delta v_{X_{i k}}\right)-\sin B_{i} \sin L_{i}\left(\Delta Y_{i k}+\Delta v_{Y_{i k}}\right)+\cos B_{i}\left(\Delta Z_{i} k+\Delta v_{Z_{i k}}\right)} \\
& \arctan \frac{-\sin B_{i} \cos L_{i}\left(\Delta X_{i j}+\Delta v_{X_{i j}}\right)-\sin L_{i}\left(\Delta Y_{i j}+\Delta v_{Y_{i j}}\right)+\cos B_{i}\left(\Delta Z_{i j}+\Delta v_{Z_{i j}}\right)}{-\sin }
\end{aligned}
$$

Zápis v programe:

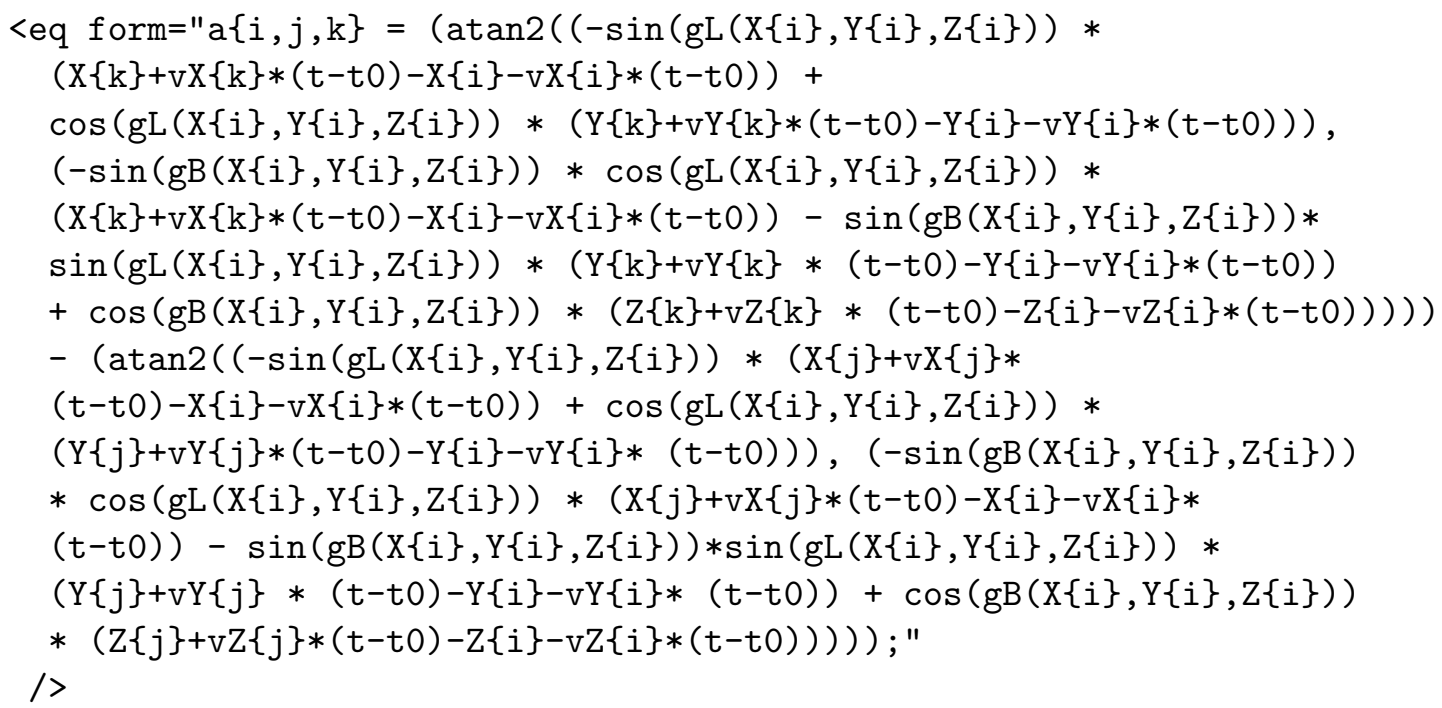

\section{Výsledky spoločného spracovania}

Výsledky spoločného riešenia GPS kampaní 2001, 2002, 2003 a terestrických observácií v epochách 1988 a 1989 s odhadom rýchlostí monitorovaných bodov sú uvedené v tabul'kách 1 , 2,3 a 4 .

\begin{tabular}{|c|c|c|c|c|c|c|}
\hline Bod & $X[\mathrm{~m}]$ & $\sigma_{X}[\mathrm{~mm}]$ & $Y[\mathrm{~m}]$ & $\sigma_{Y}[\mathrm{~mm}]$ & $Z[\mathrm{~m}]$ & $\sigma_{Z}[\mathrm{~mm}]$ \\
\hline \hline MO17 & 4036290.7995 & 4.7 & 1352165.7295 & 4.7 & 4734164.5202 & 4.7 \\
\hline MO23 & 4037308.4431 & 6.1 & 1344460.8285 & 5.7 & 4735535.1812 & 6.2 \\
\hline MO29 & 4037479.6022 & 6.4 & 1350279.8828 & 6.4 & 4733699.0043 & 6.4 \\
\hline MO24 & 4036408.9675 & 4.7 & 1345437.2847 & 4.7 & 4736041.2008 & 4.7 \\
\hline MO26 & 4036341.1893 & 4.7 & 1348846.0532 & 4.7 & 4735080.0009 & 4.7 \\
\hline MO28 & 4038676.6499 & 7.6 & 1347383.9801 & 7.6 & 4733558.2352 & 7.6 \\
\hline
\end{tabular}

Tabul'ka 1 - Odhadnuté geocentrické karteziánske súradnice bodov geodetickej siete Mochovce. 


\begin{tabular}{|c|c|c|c|c|c|c|}
\hline Bod & $v_{X}[\mathrm{~m} / \mathrm{rok}]$ & $\sigma_{v_{X}}[\mathrm{~mm} / \mathrm{rok}]$ & $v_{Y}[\mathrm{~m} / \mathrm{rok}]$ & $\sigma_{v_{Y}}[\mathrm{~mm} / \mathrm{rok}]$ & $v_{Z}[\mathrm{~m} / \mathrm{rok}]$ & $\sigma_{v_{Z}}[\mathrm{~mm} / \mathrm{rok}]$ \\
\hline \hline MO14 & 0.0059 & 5.9 & -0.0051 & 5.2 & -0.0053 & 5.9 \\
\hline MO17 & 0.0057 & 5.6 & -0.0193 & 5.6 & -0.0075 & 5.7 \\
\hline MO23 & 0.0191 & 7.6 & -0.0017 & 5.8 & -0.0043 & 8.2 \\
\hline MO29 & 0.0098 & 9.1 & -0.0141 & 9.1 & -0.0079 & 9.1 \\
\hline MO24 & 0.0050 & 5.4 & -0.0157 & 5.4 & -0.0043 & 5.5 \\
\hline MO26 & 0.0148 & 5.6 & -0.0162 & 5.6 & 0.0010 & 5.6 \\
\hline MO28 & 0.0106 & 10.0 & -0.0207 & 9.9 & 0.0050 & 10.0 \\
\hline
\end{tabular}

Tabul'ka 2 - Odhadnuté rýchlosti na bodoch geodetickej siete Mochovce.

\begin{tabular}{|l|c|c|c|c|c|c|}
\hline Bod & $\mathrm{B}\left[^{\circ}\right]$ & $\sigma_{B}["]$ & $\mathrm{L}\left[^{\circ}\right]$ & $\sigma_{L}["]$ & $\mathrm{H}[\mathrm{m}]$ & $\sigma_{H}[\mathrm{~mm}]$ \\
\hline \hline MO17 & 53.589713 & 0.0002 & 20.578845 & 0.0003 & 213.2505 & 6.4 \\
\hline MO23 & 53.609830 & 0.0002 & 20.464701 & 0.0003 & 252.8440 & 6.4 \\
\hline MO24 & 53.617262 & 0.0002 & 20.482827 & 0.0003 & 267.6758 & 4.7 \\
\hline MO26 & 53.603304 & 0.0003 & 20.531516 & 0.0004 & 226.3663 & 7.6 \\
\hline MO28 & 53.580117 & 0.0002 & 20.499716 & 0.0003 & 258.4968 & 5.4 \\
\hline MO29 & 53.582673 & 0.0002 & 20.546452 & 0.0003 & 218.3034 & 4.7 \\
\hline
\end{tabular}

Tabul'ka 3 - Elipsoidické súradnice bodov siete na elipsoide WGS-84, na ktorých sa uskutočnili 2, resp. 3 merania GPS.

\begin{tabular}{|c|c|c|c|c|c|c|}
\hline Bod & $v_{n}[\mathrm{~m} / \mathrm{rok}]$ & $\sigma_{v_{n}}[\mathrm{~mm} / \mathrm{rok}]$ & $v_{e}[\mathrm{~m} / \mathrm{rok}]$ & $\sigma_{v_{e}}[\mathrm{~mm} / \mathrm{rok}]$ & $v_{v}[\mathrm{~m} / \mathrm{right}]$ & $\sigma_{v_{v}}[\mathrm{~mm} / \mathrm{rok}]$ \\
\hline \hline MO17 & -0.0045 & 6.9 & -0.0201 & 5.2 & -0.0061 & 9.1 \\
\hline MO23 & -0.0160 & 9.10 & -0.0076 & 9.1 & 0.0085 & 9.1 \\
\hline MO24 & -0.0027 & 5.6 & -0.0164 & 5.6 & -0.0034 & 5.6 \\
\hline MO26 & -0.0060 & 9.9 & -0.0201 & 9.9 & 0.0067 & 10.1 \\
\hline MO28 & 0.0007 & 4.9 & -0.0229 & 5.8 & 0.0060 & 4.7 \\
\hline MO29 & -0.0088 & 5.4 & -0.0165 & 5.3 & -0.0027 & 5.6 \\
\hline
\end{tabular}

Tabul'ka 4 - Odhadnuté rýchlosti bodov transformované do zložiek v horizontálnej rovine a vo výške.

\section{Záver}

V článku sme sa zamerali na obecný popis univerzálneho softvérového prostredia, orientovaného na modelovanie, analýzu a spracovanie najmä geodetických sietí. Teoretické základy softvéru sú položené do oblasti matematiky, resp. numerickej matematiky, informatiky, geodézie a štatistiky. V aplikácii je možné využit nielen matematické modely na riešenie geodetických sietí naznačené v tomto článku, ale prakticky l’ubovol’né matematické modely využitelné na vyrovnanie geodetických sietí.

Program umožňuje spracovávat observácie opakovaných meraní (etapových, epochových a permanentných), ako aj kombinácie terestrických meraní s družicovými meraniami. Uplatnenie nachádzajú napr. terestrické merania včlenené do riešenia družicovej siete, kde umožňujú zlepšit jej geometriu, výškovú zložku a pod.

Variabilnost programu v definovaní matematických modelov umožňuje ich rýchlu modifikáciu, čo dovoluje zamerat’ sa predovšetkým na samotné modelovanie skúmanej geodetickej siete. Táto volnost’ $\mathrm{v}$ definícii matematických modelov umožňuje nielen separované spracovanie a analýzu jednorozmerných, dvojrozmerných, trojrozmerných a štvorrozmerných geodetických 
sietí, ale aj ich modifikácie ako aj ich vzájomné kombinovanie s využitím globálnej kovariančnej matice. Matematický model, resp. observačné rovnice tvoriace matematický model, sú v programe implementované vo forme rovníc zapísaných v symbolickom tvare.

Praktickú funkčnost' programu sme demonštrovali na riešení viacepochovej heterogénnej geodetickej siete.

\section{Referencie}

1. Čepek, A.: The GNU Gama project - Adjustment of Geodetic Networks, Acta Polytechnica, Vol. 42, No. 3, 2002.

2. Dobeš, J. et. al.: Presné lokálne geodetické siete. Edícia Výskumného ústavu geodézie a kartografie v Bratislave, Bratislava, 1990.

3. Gerhátová, L'. Integrované spracovanie družicových a terestrických meraní - dizertačná práca, Bratislava, 2002.

4. Harold, E. R., Means, W. S.: XML in a Nutshell, 2nd Edition, O'Reilly, 2002.

5. Hefty, J.: Globálny polohový systém v štvorrozmernej geodézii, Bratislava, 2003.

6. Hefty, J.: Monitorovanie recentných pohybov litosféry v lokalite atómovej elektrárne Mochovce pomocou geodetických metód, Správa k úlohe v rámci Zmluvy o dielo 04085-02, STU Bratislava, 2002.

7. Hefty, J.: Geologické hodnotenie oblasti EMO, Meranie recentných pohybov v lokalite EMO, STU Bratislava, 2004.

8. Charamza, F.: GSO - An Algorithm for Solving Linear Least Squares Problems with Possibly Rank Deficient Matrices, Referát VÚGTK, Praha, 1977.

9. Klobušiak, M.: WIGS - Integrované geodetické siete, transformácie, spájanie, porovnanie, výpočet rýchlostí bodov a transformácie S-JTSK do xTRSYY [Programový systém WIGS 4.2002], VÚGK \& MaKlo, Bratislava, 1995-2002.

10. Kubáčková, L.: Metódy spracovania experimentálnych meraní, Veda, 1990. 